\title{
HOMEOPATIA: PRÁTICA MÉDICA HUMANÍSTICA
}

\section{Marcus Zulian TeIXeIRA}

Trabalho realizado pela Disciplina "Fundamentos da Homeopatia-MCM0773" da Faculdade de Medicina da Universidade de São Paulo, São Paulo, SP

*Correspondência

Rua Teodoro Sampaio, 352/128

São Paulo - SP

Cep 05406-000

Tel.: (11) 3083-5243

Fax: (11) 3082-6980

marcus@homeozulian.med.br

\section{RESUMO}

$\mathrm{Na}$ última década, o modelo médico vigente busca resgatar um incremento na relação médico-paciente, com propostas de humanizaçãa nas áreas da educação, assistência e política médica. Valorizar características holísticas das práticas não convencionais em saúde sugere a incorporação de aspectos diversos das ciências humanas no entendimento do processo de adoecimento do indivíduo, ressaltando que 0 interesse do médico por aspectos aparentemente não relacionados ao órgão acometido (história de vida do paciente, personalidade, interesses etc.) deve ser acrescentado à consulta médica técnica e não-humanizada. Tendo em vista que a homeopatia utiliza esta ampla abordagem semiológica como prática inerente, empregando a totalidade de sintomas característicos do enfermo para avaliar o desequilibrio orgânico e escolher o meio de tratamento, a prática clínica homeopática tem muito a contribuir com o humanismo da medicina.

Unitermos: Homeopatia. Saúde holística. Relação médico-paciente. Humanismo. Humanização da assistência. Semiologia homeopática.

\section{INTRODUÇÃO}

Com os avanços da fisiologia integrativa, que busca compreender o ser humano como uma unidade psico/neuro/imuno/ endócrino/metabólica interativa, ao invés de um conjunto de sistemas fisiológicos distintos e isolados, o binômio saúde/doença passa a ser estudado segundo uma abordagem dinâmica, integrada e multifatorial, em vista dos aspectos bio/psico/sócio/espirituais que definem a individualidade humana.

A fim de que a prática médica rotineira englobe esta complexidade humana, a medicina reducionista cede espaço à medicina humanística, com propostas inovadoras no campo da educação, assistência e política médica, para que este novo conceito de saúde possa ser transmitido à população segundo os pressupostos de integralidade, eqüidade e universalidade propostos pelo Sistema Único de Saúde (SUS).

Na educação médica, Martins' descreve os quesitos para uma formação humanizada e ética dos futuros profissionais:

"As escolas médicas devem, também, deixar claro, em todos os momentos do curso, que um médico deve ter uma alta competência técnica, mas deve também ter uma formação humanística e ética, e atuar de forma socialmente responsável. Os médicos com quem os estudantes convivem devem ter claro que jamais estarão ensinando apenas sua área de conhecimento, mas estão sendo modelo de atendimento aos pacientes. Outro desafio para o século XXI é o currículo médico se adequar à visão moderna de saúde, que envolve fatores biológicos, psicológicos, sociais, ambientais, hábitos e estilo de vida e acesso aos serviços de saúde. A promoção da saúde, a prevenção, a busca da qualidade de vida, a reabilitação e a reintegraçãa à sociedade passam a ser tão importante como o diagnóstico e tratamento das diversas enfermidades".

Além da necessidade de construir uma sociedade igualitária, aliando os ideais políticos com a promoção da saúde, Ferreira e
Silva ${ }^{2}$ sugerem, como propostas assistenciais para uma medicina mais humanizada, o desenvolvimento de projetos na área da medicina preventiva, a consolidação do Programa de Saúde da Família (PSF), a valorização de práticas alternativas de saúde (fitoterapia, acupuntura e homeopatia), dentre outras.

Assim como acontece com a população mundial, cresce entre a classe médica (estudantes, residentes e médicos) a aceitação e a procura por práticas não convencionais em saúde, devido às suas características humanísticas: ampliam o entendimento do binômio saúde/doença (interconexão corpo/mente/espírito), favorecem a relação médico-paciente e incrementam a resolutividade clínica das doenças crônicas sem os prováveis efeitos adversos das drogas clássicas ${ }^{3}$.

Segundo estes enfoques, a prática médica homeopática contribui à humanização da medicina, por utilizar visão antropológica e abordagem semiológica holísticas, valorizando os múltiplos aspectos da individualidade humana no processo de adoecimento e na escolha da substância curativa. Da mesma forma que esta "individualização" exige tempo maior de consulta e acompanhamento para que $\mathrm{o}$ entendimento do doente e a correspondente adequação terapêutica sejam realizadas, a dinâmica semiológica homeopática clássica, que prioriza a escuta de todas as queixas do enfermo, incrementa a relação médico-paciente, fator indispensável para uma medicina humanizada.

\section{Homeopatia e humanismo}

$\mathrm{Na}$ busca por uma terapêutica menos iatrogênica do que a medicina heróica de sua época (séculos XVIII-XIX), que se esforçava para expulsar a imaginária materia peccans por meio de sangrias, eméticos, laxantes, sudoríferos, diuréticos etc., espoliando o organismo das forças e dos humores vitais indispensáveis à manutenção da saúde, 
Samuel Hahnemann, fundador do modelo homeopático, aplica princípios éticos e humanísticos ("beneficência" e "nãomaleficência") ao elaborar uma prática médica que visa estimular as forças curativas do organismo sem os efeitos nefastos das altas doses dos medicamentos heróicos.

Inter-relacionando as ciências humanas ou humanidades com a medicina, Hahnemann incorporou aspectos antropológicos, filosóficos, sociológicos e psicológicos na compreensão do binômio saúde/doença, empregando conceitos do modelo médico vitalista, predominante em sua época:

"No estado de saúde do indivíduo reina, de modo absoluto, a força vital de tipo não-material que anima o corpo material (organismo), mantendo todas as suas partes em processo vital admiravelmente harmônico nas suas sensações e funções, de maneira que nosso espírito racional que nele habita, possa servir-se livremente desse instrumento vivo e sadio para um mais elevado objetivo de nossa existência". (Organon da arte de curar, §9)

Criticando qualquer especulação metafísica sobre a natureza desta "força vital", entende-se o processo de adoecimento como um enfraquecimento dos mecanismos fisiológicos normais de adaptação e compensação, correlacionando este desequilíbrio orgânico às diversas manifestações sintomáticas do indivíduo (pensamentos, sentimentos, sensações, desejos e aversões, predisposições climáticas, aspectos do sono etc., além dos aspectos clínicos habituais), utilizando esta "totalidade de sintomas" como referencial para diagnosticar o padecimento da força vital (predisposição individual, suscetibilidade mórbida ou desequilíbrio homeostático) e para prescrever, segundo o princípio da similitude, os medicamentos que despertavam um conjunto de sintomas semelhantes nos indivíduos sadios (similia similibus curentur).

Ao valorizar a totalidade de sintomas característicos na individualidade enferma, tanto no entendimento da doença, quanto na escolha do meio de cura, pressupõe-se fundamentos da fisiologia integrativa moderna, priorizando as manifestações sintomáticas do estado psíquico-emocional por observar, segundo uma concepção psicossomática ou holística do adoecimento humano, que "em todas as doenças físicas, a disposição psíquica e mental está sempre se modificando e, em todos os casos de doença, que devem ser curados, o estado psíquico deve concorrer como um dos mais notável no conjunto característico dos sintomas, se quisermos traçar um quadro fidedigno da doença, a fim de poder tratá-la homeopaticamente, com êxito". (Organon, §210)

Ao detalhar a abordagem semiológica homeopática (Organon, §83-104), Hahnemann inicia as instruções para a realização deste "exame individualizador de um caso de doença", enfatizando a importância de saber ouvir todas as queixas do paciente, observando e anotando atentamente tudo o que esteja fora do comum, a fim de que o conjunto de particularidades possa ser apreendido e utilizado na escolha do medicamento específico:

"O doente se queixa do desenvolvimento de seus males; as pessoas que o rodeiam relatam suas queixas, seu comportamento e o que perceberam nele; o médico vê, ouve e observa com os demais sentidos o que há nele de alterado ou fora do comum. Escreve exatamente tudo o que o paciente e seus amigos the disseram, com as mesmas expressões por eles utilizadas. Se possível, permanece em silêncio deixando-os falar sem interrompê-los, a menos que se desviem para outros assuntos (pois cada interrupção perturba o encadeamento do pensamento do narrador, posteriormente não the ocorrendo de novo tudo exatamente como ele pretendia dizer a princípio). [...]". (Organon, $\S 84)$

Desta forma, o médico homeopata que se propõe seguir a técnica semiológica correta, a fim de diminuir as possíveis falhas na escolha do tratamento apropriado, deve esforçar-se a conhecer as suscetibilidades mórbidas individuais, realizando uma anamnese detalhada e humanizada, interessando-se genuinamente por todas as nuances do paciente (mesmo aquelas não relacionadas diretamente à "enfermidade" ou ao "órgão doente", como "sua história de vida, sua personalidade, seus interesses"), buscando "enxergar a dimensão pessoal do outro", como descreve Giglio ${ }^{5}$ na sua proposta para a humanização dos médicos:

"O médico humanizado ouve com interesse seus pacientes. Como vimos, ouvir aprimora a pessoa do médico, dá-lhe mais satisfação profissional, além de aumentar também a satisfação de seus pacientes. Contextualizado ou não pelo conhecimento das humanidades, o que quer que os pacientes the contem durante sua vida profissional por si só aumentará o seu interesse no lado pessoal de seus próprios pacientes. Ouvir é, portanto, a habilidade a ser cultivada para que nosso exercício profissional seja continuadamente renovado e dinamizado por nossos pacientes que, sob o pretexto de um sintoma ou doença, venham a nos procurar para estabelecer um relacionamento profissional e humano aprofundado que é a base da relação médico-paciente".

\section{Conflito de interesse: não há.}

\section{SUMMARY}

\section{Homeopathy: a humanistic approach to medical practice}

During the last decade, the traditional medical model has endeavoured to retrieve an improvement in the patient-physician relationship by means of propositions for humanization in the areas of education, medical care and policies. To enhance holistic characteristics of non-conventional practices in health, the incorporation of several aspects of humanities in understanding the process of the individual's illness, stressing that the physician's interest in aspects apparently not related to the impaired organ (history of the patients life, personality, interests, etc.) should be added to the technical and less humanized consultation. Since homeopathy embraces this wide semiological approach as inherent practice, using the totality of characteristic symptoms to evaluate organic unbalance and choose means of treatment, homeopathic clinical practice can signnificantly contribute to humanism in medicine. [Rev Assoc Med Bras 2007; 53(6): 547-9]

KEY wORDS: Homeopathy. Holistic health. Patient physician 
relationship. Humanism. Humanization of assistance. Homeopathic semiology.

\section{REFERÊNCIAS}

I. Martins MA. Ensino médico [editorial]. Rev Assoc Med Bras. 2006;52(5): 282.

2. Ferreira ILM, Silva TPT. A humanização da medicina no Brasil: reflexões. Rev Assoc Med Bras. 2007;53(3):206.

3. Teixeira MZ, Lin CA, Martins MA. O ensino de práticas nãoconvencionais em saúde nas faculdades de medicina: panorama mundial e perspectivas brasileiras. Rev Bras Educ Med. 2004;28(I):5I-60.
4. Hahnemann S. Organon da arte de curar. 2a ed. Tradução de: Organon der Heilkunst. Ribeirão Preto: Museu de Homeopatia Abrahão Brickmann, 1995.

5. Del Giglio A. Medicina e humanismo [editorial]. Rev Assoc Med Bras. 2007;53(3): 191-2.

Artigo recebido: 19/07/07

Aceito para publicação: 03/08/07 